\title{
EDUCAÇÃO AMBIENTAL NO MEIO AMBIENTE DIGITAL: ESPAÇO DE EFETIVAÇÃO DO DIREITO FUNDAMENTAL À EDUCAÇÃO
}

\author{
Marília Longo do Nascimento*
}

\section{INTRODUÇÃO}

A análise jurídica e educacional do tema proposto "educação ambiental no meio ambiente digital"1 , vale-se das ciências jurídicas e sociais e das ciências da educação, numa perspectiva interdisciplinar, como exigência metodológica, para a compreensãoda função social do meio ambiente digital na construção de ações compatíveis com os direitos fundamentais.

0 enfoque é dado a partir do direito ambiental e sua interface com o direito eletrônico, considerando o direito ambiental na sua perspectiva multidimensional, como forma de unir estas diferentes disciplinas entorno do tema educação ambiental no meio ambiente digital. A educação é analisada sob o viés dos direitos fundamentais, e o meio ambiente digital a partir de sua função social.

* Presidente da Comissão de Direito Ambiental da OAB/RS, Mestre em Direito Ambiental pela Universidade Panthéon-Sorbonne

1 O presente artigo é o resultado da pesquisa desenvolvido para a participação desta autora na IV Jornadas Luso-Brasileiras de Direito Ambiental, do Instituo de Direito Brasileiro da Faculdade de Direito da Universidade de Lisboa, e também integrará a obra "A Função Social da Tutela Jurídica do Meio Ambiente Digital", organizado pelos os professores doutores Celso Antonio Pacheco Fiorillo, Luiz Oosterbeek e Pablo Jiménez Serrano. 
Ao se fazer a interface dos dois ramos do direito analisa-se as trocas sociais ali praticadas, através da troca de informações e comunicação em rede por meio da Educação Ambiental. 0 questionamento proposto, portanto, é saber como realizar a educação ambiental no meio ambiente digital de forma que ela seja capaz de contribuir para uma política ambiental sustentável, compatível com a dignidade da pessoa humana.

Pode-se, desde já, afirmar que a educação ambiental enfrenta na atualidade o necessário processo de mudança de suporte das informações para o meio ambiente digital (RODRIGUES, COLENSATI, 2008), alterando as formas de pensar, com um funcionamento em rede. 0 que resulta em formas de comunicação e aprendizagem diferentes das tradicionalmente utilizadas e implica também numa mudança de rumo na relação entre comunicação e educação.

No Brasil, a Constituição Federal impôs como dever do Poder Público "promover a educação ambiental em todos os níveis de ensino e a conscientização pública para a preservação do meio ambiente" (art. 225, VI), decorrente do direito social à educação (art. 6ㅇ).

Atendendo à referida norma constitucional, hoje contamos com um marco regulatório específico sobre o tema, a Lei n.․ㅡ 9.795/99, que aprovou a Política Nacional de Educação Ambiental, como sendo um "componente essencial e permanente da educação nacional" (art. $2^{\circ}$ ).

De forma a conciliar nossos temas de estudos, olha-se para o direito digital. 0 Marco Civilda Internet brasileiro, Lei n. $\underline{o}$ 12.965/14, reforçou o dever constitucional do Estado de prestar educação, em todos os níveis de ensino, incluindo a "capacitação integrada a outras práticas educacionais, para o uso seguro, consciente e responsável da internet como ferramenta para o exercício da cidadania, a promoção da cultura e o desenvolvimento tecnológico"(art. 26). 
Diante da conjuntura posta, cumpre avaliar os fundamentos jurídicos, sociais e educacionais, sob este enfoque multidisciplinar, da inclusão do processo de educação ambiental no meio ambiente digital, passando num primeiro ponto a avaliar o histórico e atualidade da educação ambiental; e no segundo ponto, a identificar os fundamentos que fortalecem e embasam o necessário processo de concretização do direito à educação face à função social da tutela do meio ambiente digital.

\section{EDUCAÇÃO AMBIENTAL: CONSTRUÇÃO HISTÓRICA E REFERÊNCIAS DA ATUALIDADE}

Conceituada na legislação brasileira como "os processo por meio dos quais o indivíduo e a coletividade constroem valores sociais, conhecimentos, habilidades, atitudes e competências voltadas para a conservação do meio ambiente" ${ }^{2}$, a educação ambiental conta com uma história de pouco mais de quarenta anos, como resposta mundial da educação frente a crise ambiental.

De natureza híbrida, a educação ambiental foi sendo construída a partir de elementos de diversas disciplinas tais como as ciências educativas, as ciências sociais e as ciências naturais, para contemplar seus dois objetivos,a educação e a proteção do meio ambiente, como áreas do conhecimento e de intervenção (CARTEA, 2009).

Esta natureza multidisciplinar ${ }^{3}$ não é apenas um reflexo de uma construção histórica, mas é defendida na doutrina por diversos estudiosos como uma necessidade metodológica, a exemplo de BACHIORRI (1996 apud COLENSANTI, RODRIGUES), ao sustentar que a pesquisa e construção da educação ambiental deve abarcar

\footnotetext{
Art. $1^{\circ}$ da Lei n. ${ }^{\circ}$ 9.795/99, que dispões sobre a educação ambiental, institui a Política Nacional de Educação Ambiental, e dá outras providências.

3 Para um aprofundamento e compreensão da multidisciplinaridade como metodologia da investigação científica com a participação de mais de uma disciplina, vide "Aspectos conceituais da multidisciplinaridade e da interdisciplinaridade e a pesquisa em ciência da informação"(BICALHO; OLIVEIRA).
} 
estudos produzidos por distintas disciplinas, com o objetivo de promover comportamentos individuais e coletivos ambientalmente responsáveis com o meio ambiente. Nesta linha é unanime a posição de que a Educação Ambiental deve contemplar todas as possíveis etapas do processo educativo formal e não formal ${ }^{4}$.

Por motivos bastante lógicos, pois o objetivo é comum, esta natureza da educação ambiental caminha ao lado da realidade do campo de estudo do direito ambiental. A interdisciplinaridade, que busca a união de diferentes disciplinas para tratar de um tema comum, como bem leciona FIORILLO (2015, p. 123), ao abordar o encontro do direito eletrônico e do direito ambiental é marcada por"intensidades de trocas sociais que ocorrem por meio das redes informacionais e a busca de patamares de desenvolvimento capazes de produzir menor impacto ambiental".

Ao se chegar neste estágio de compreensão da educação ambiental, sua construção acompanhou o desenvolvimento e amadurecimento do debate ambiental no âmbito internacional, a partir das primeiras grandes Conferências. Sua breve história, que racionaliza a problemática ambiental, passa por três fases bem definidas, até se chegar na atualidade, que poderá ser considerada como a quarta fase de sua percepção e consolidação. Fase esta ainda em curso, diretamente impactada e moldada pelo uso das novas tecnologias, em face sociedade da informação (SIQUEIRA JR., 2007) que alterou a forma de relacionamento e comunicação entre educadores e educandos, cidadãos e Estado, indivíduos e instituições.

4 Acompanhando esta posição universal, a política brasileiras e seus planos e programas de educação ambiental orientam que ela seja transversal, em todos os níveis da educação formal e também deva ser promovida na educação informal, à todos os cidadãos, aos empregados, nas entidades de classes, em todos os meios de comunicação. 


\subsection{A CONSTRUÇÃO HISTÓRICA DA EDUCAÇÃO AMBIENTAL}

Sem querer simplificar o tema e resumir uma construção complexa e nem sempre linear, depreende-se da história que a educação ambiental se dividi em três grandes etapas de sua existência, e podemos considerar que a partir do incremento do uso dos meios digitais constrói-se o atual momento desta história. Ainda que marcada por um histórico de quatro décadas, ao se pesquisar sobre o tema, evidencia-se uma ausência de unicidade e de referencial teórico (PEDRINI, 1997).

A primeira etapa da construção do que hoje conhecemos como educação ambiental vai até o final da década de 60, início da década de 70, ao lado dos passos dados pelas ideiasconservacionistas e preservacionistas, centrado na ecologia, a partir do reconhecimento e conhecimento do Meio Ambiente. Nesta fase não se definiu propriamente a educação ambiental enquanto uma disciplina, mas ela é marcada pelo início dos esforços para lhe definir um conteúdo mínimo, através de elementos pedagógicos para explicar poluição, preservação das espécies e espaços naturais (CARTEA, 2009).

A preocupação ambiental nasce no século XIX, a partir de estudos naturalistas europeus, sobre a transformação das cidade pela ação humana, marcadas pela poluição e crescimento populacional. Ideias presentes também nos Estados Unidos da América, que impulsionaram a criação do primeiro Parque natural do mundo, como um espaço de conservação e de recreação para as populações urbanas ${ }^{5}$. A Revolução Industrial e seus efeitos nefastos para a saúde humana e qualidade ambiental ${ }^{6}$ também impulsionaram o debate e a construção da educação ambiental ${ }^{7}$.

\footnotetext{
5 Assentado em 800 mil hectares, o Parque Nacional de Yellowstone foi criado em 1872. Para maiores informações vide GODOY, Larissa R. C. "O modelo de gestão e o financiamento de áreas protegidas nos Estados Unidos da América”.

6 Um dos grandes eventos que marcou esta época é o denominado Grande Nevoeiro na cidade de Londres, em 1952, que matou 4.000 por poluição atmosférica.

7 Um dos principais estudiosos evolucionistas da época, Patrick Geddes, que estudou as transformações sociais e suas relações com o meio ambiente, publicou o livro "Cidades em Evolução" de 1915, abordou temas de educação ambiental. http://www.labeurb.unicamp.br/endici/index.php?r=verbete/view\&id=40
} 
O primeiro conceito de educação ambiental, ainda considerado dentro da primeira fase, nasce através da "InternationalUnion for theConservationofNature”, em 1971. (COLENSANTI, RODRIGUES, 2008).

A segunda fase da educação ambiental, compreendida entre os anos 70 e 80, foi marcada pelas Conferências Internacionais de Meio Ambiente. A partir de 72, com a Conferência Internacional sobre o Meio Ambiente de Estocolmo, a concepção trazida em 71 ganha um novo elemento, o da inclusão do homem como peça fundamental para a proteção do Meio Ambiente. É na I Conferência Intergovernamental de Tbilisi de 1977, organizada pela UNESCO ${ }^{8}$, que, para além de uma conceituação, são traçados princípios, objetivos, características e estratégias de educação ambiental.

Nesta etapa, a educação ambiental focou sua atenção em fatores determinantes do comportamento humano a favor ou contra o meio ambiente. Acreditava-se que os problemas ambientais decorriam de condutas irracionais, inconscientes ou irresponsáveis de pessoas e coletividades. Estas variáveis foram utilizadas para construir programas e ações educativas ambientais.

É nesta fase também que a interdisciplinaridade surge como uma das principais características da Educação Ambiental, pois olha-se para as ciências e tecnologia como aliados para a solução dos problemas ambientais globais, na busca de soluções de ordem mundial, compatíveis com o crescimento econômico.

A terceira fase, que se inicia no final dos anos 80, é marcada pela evolução na tentativa de uma construção metodológica da educação ambiental, cada vez mais fortalecida pelas Conferências Internacionais, agora dedicadas exclusivamente no tema, marcadas pela mudança de paradigmas nas pesquisas em matéria de educação ambiental, alterando a lógica construída até então.

Nos eventos que ocorreram durante a Conferência das Nações Unidas sobre o Meio Ambiente e Desenvolvimento - RIO-92,

8 Resumo da Conferência: http://www.mma.gov.br/port/sdi/ea/deds/pdfs/decltbilisi.pdf 
incorporou-se mais um elemento ao primeiro conceito de educação ambiental: a sociedade. Dentre os documentos aprovados durante a Conferência, merece destaque a "Carta da Terra", que no seu item $14^{9}$, confirma que no processo educativo deve-se incorporar informações sobre o modo de vida sustentável. $\mathrm{Na}$ Agenda $21^{10}$, o documento oficial da Conferência, no seu capítulo 36, a ênfase à educação ambiental continuada e a incorporação do desenvolvimento sustentável nas orientações ao ensino. Por fim, juntamente com a Carta da Terra, nos eventos paralelos à Conferência, no Fórum Global 92, foi aprovado o Tratado de Educação Ambiental para Sociedades Sustentáveis e Responsabilidade Global, reconhecendo-a como um processo social permanente.

Mas o principal marco desta terceira etapa,é a realização, na década de 90, de grandes conferências sobre o tema específico da Educação Ambiental ${ }^{11}$, que marcam a construção de uma nova geração de educação ambiental, baseadana ideia de democracia participativa. Antes via-se pelo viés da qualificação, passa-se para o da ação. Ação, com a participação de todas os envolvidos no processo educativo, como um valor fundamental e que assume a complexidade social e cultural da problemática ambiental.

É neste época que surgem os marcos legais da educação ambiental. Em Portugal, a Lei de Bases do Sistema Educativo de $1986^{12}$ reconheceu a educação ambientalnos objetivos de formação dos alunos, em todos os níveis de ensino, tema retomado no Plano Nacional de Política de Ambiente português aprovado em 1995, dedicando capítulo específico sobre o tema. No mesmo período, a Espanha promove sua reforma educativa, aprovando a Lei Orgânica do Sistema Educativo em

9 http://www.mma.gov.br/estruturas/agenda21/_arquivos/carta_terra.pdf

$10 \mathrm{http}: / / w w w . m m a . g o v . b r / r e s p o n s a b i l i d a d e-s o c i o a m b i e n t a l / a g e n d a-21 / a g e n d a-$ 21-global

11 Histórico Mundial da Educação Ambiental: http://www.mma.gov.br/educacao -ambiental/politica-de-educacao-ambiental/historico-mundial

12 Lei n. ${ }^{\circ} 46 / 86$, de 14 de outubro. 
03 de outubro de 1990, que inclui a Educação Ambiental como conteúdo transversal ${ }^{13}$.

O Brasil acompanha ativamente este processo. Em 1999publica a Lei n.ㅇ 9.795, regulamentada em 2002 pelo Decreto n.ㅇ 4281, que inclui o meio ambiente no parâmetro curricular nacional ${ }^{14} \mathrm{e}$ cria o Programa Nacional de Educação ambiental.

A breve história da educação ambiental acompanha o dinamismo e a evolução da questão ambiental mundial, que hoje não pode tomar outro rumo que não o de integrar na sua caminhada o debate e a construção do tema no meio ambiente digital, Marcada pela ausência de uma metodológia bem definida, o atual desafio amplia seu espectro, onde encontra novas dinâmicas entre educandos e educadores, bem como a não linearidade das informações neste ambiente.

\subsection{A ATUALIDADE DA EDUCAÇÃO AMBIENTAL NO BRASIL \\ 0 atual estágio da educação ambiental é marcado no seu} processo evolutivo pelo assentamento em bases participativas, de estimulo ao pensamento crítico e propositivo dos educandos e da comunidade, através de diversos espaços de comunicação e com apoios tecnológicos diferenciados. Ao professor cumpre usar estratégias inovadoras em aula, para promover a interação em redes de conhecimento, na sociedade da informação.

Surgem, portanto, novas relações entre docentes e alunos, e desses com o meio ambiente. $\mathrm{Na}$ atualidade, crianças e jovens manuseiam e utilizam os meios eletrônicos cotidianamente, esta geração e a primeira a ser educada no meio digital, e gera uma ruptura com os padrões de ensino e aprendizagem clássicos. A comunicação autoritária e verticalizada, centrada na informação

13 A Lei, denominada de LOGSE, tem como norte o respeito às diversidade, sem renunciar ao caráter de educação igual para todos. Vide em: MOREIRA, Antônio Flávio. Políticas e Práticas. Campinas: Papirus, 1999.

14 A educação ambiental não havido sido incluído na Lei de Direitrizes Básicas da Educação - LDB, n.9.394/96. 
dada do professor ao aluno, ainda amplamente utilizada nas salas de aulas, não e suficiente para a educação na sociedade da informação (USEDA e outros, 2015).

A multidisciplinaridade do tema tem sido incorporada cada vez mais em novas ciências e áreas, tais como na justiça social, saúde, unidades de conservação, atividades industriais, entidades de classes e direitos sociais. As normas nacionais se dedicaram a regrar o tema da educação ambiental e impulsionaram planos e programas governamentais, além de políticas empresariais de responsabilidade socioambiental.

O legislador nacional debruçou-se sobre o tema da educação ambiental de forma expressa pela primeira em 1981, com a publicação da Política Nacional do Meio Ambiente (art. 2º, $\mathrm{X}^{15}$ ), norma integralmente recepcionada pela Constituição Federal de 1988. No capítulo dedicado à ordem social, foi garantido no art. 225 a todos o direito ao meio ambiente ecologicamente equilibrado, devendo o Poder Público e a coletividade defende-lo e preserva-lo para as presentes e futuras gerações. Uma das formas de dar efetividade ao direito e dever inscritos no caput do mencionado artigo, é através da educação ambiental em todos os níveis de ensino e a conscientização pública para a preservação do meio ambiente $\left(\S 1^{\circ}\right.$, inciso VI).

A partir do reconhecimento constitucional, a educação ambiental passou a ser um dever de Estado, ainda assim, foi apenas no final da década de 90, em resposta à consistência internacional do tema que orientava medidas regionais e locais como resposta à crise ambiental e como meio para uma sociedade sustentável, que foi criada a Política Nacional de Educação Ambiental ${ }^{16}$. Já é neste instrumento que se dá o encontro da educação ambiental com

15 "X - educação ambiental a todos os níveis de ensino, inclusive a educação da comunidade, objetivando capacitá-la para participação ativa na defesa do meio ambiente."

16 Lei Federal n. ${ }^{\circ}$ 9.795/99. 
as novas tecnologias ${ }^{17}$, como uma forma de propagar, com maior alcance e efetividade, aconscientização, a informação e a compreensão do papel do cidadão e da sociedade com o meio ambiente.

Para além de uma análise pura da lei da educação ambiental, o estudo da atual conjuntura nacional passa necessariamente pela compreensão dos deveres do Estado de defesa e proteção do meio ambiente e de promoção da educação.

A Constituição Federal reconheceu no art. 6o o direito de todos à educação, reconhecido como um direito fundamental de caráter social (DUARTE, 2007); a importância de identifica-lo como tal são implicações dele decorrentes, especialmente quanto aos deveres do Poder Público de efetividade deste direito ${ }^{18}$.Se educação e defesa e proteção do meio ambiente são deveres do Estado e direito de todos, as políticas públicas deve ser orientandas à efetivação deste direito.

Segundo Paulo Affonso Leme Machado (2014), o não cumprimento deste dever, por parte do Estado, de inclusão da educação ambiental é considerada uma irregularidade e a autoridade competente será responsabilizada: "A ação civil pública será meio adequado para promover a obrigação de se ministrar a educação ambiental".

Através do Programa Nacional de Educação Ambiental ${ }^{19}$, o Governo Federal traz a orientação nacional e plano de ações para a educação integrada à sustentabilidade ambiental, em busca do "desenvolvimento do país, buscando o envolvimento e a participação social na proteção, recuperação e melhoria das condições ambientais e de qualidade de vida", a partir das seguintes diretrizes:

17 Art. $5^{\circ}$, VI e art. $8^{\circ}, \S 3^{\circ}$, II.

18 "A educação, direito de todos e dever do Estado e da família, será promovida e incentivada com a colaboração da sociedade, visando ao pleno desenvolvimento da pessoa, seu preparo para o exercício da cidadania e sua qualificação para o trabalho", art. 205 da Constituição Federal.

$191^{\text {a }}$ versãofoipublicadaem 2005. A $2^{\text {a }}$ versão é de 2014, do ProNEA: http://www. mma.gov.br/images/arquivo/80221/pronea_4edicao_web-1.pdf 
-Transversalidade e Interdisciplinaridade.

-Descentralização Espacial e Institucional.

-Sustentabilidade Socioambiental.

-Democracia e Participação Social.

-Aperfeiçoamento e Fortalecimento dos Sistemas de Ensino, Meio

-Ambiente e outros que tenham interface com a educação ambiental.

O Brasil ainda passa por um processo de adaptação ao planejamento de longo prazo, propostos à partir das Políticas Nacionais, e de seus decorrentes planos e programas.

No âmbito da educação ambiental, os estudiosos percebem que, a despeito de uma intensificação na sua produção, os materiais pedagógicos relacionados ao meio ambiente não refletem, na sua grande maioria os objetivos explicitados no Programa Nacional. 0 desafio é não só o de construir um diálogo comum, mas de adapta-lo às realidades locais e aos segmentos sociais (RODRIGUES, COLESANTI, 2008).

Se a ausência de um referencial teórico e de respeito a um eixo central orientador, a educação ambiental enfrenta uma questão ainda mais complexa ${ }^{20}$, ante a ausência de uma linguagem estável, sustentada nas novas tecnologias, marcada por um forte caráter de experimentação, e também por uma simples transferência de suporte de materiais e métodos tradicionais para conteúdos digitais. Usa-se da linguagem tradicionalmente usada nas salas de aulas e materiais impressos, para o meio ambiente digital, espaço complexo e multifacetado.

20 O termo "complexa" aqui trazido não diz respeito à complexidade da questão ambiental, mas da problemática da construção de um referencial teórico para a educação ambiental, especialmente no meio ambiente digital, fazendo referencia à teoria da complexidade de Edgar Morin. Vide: PIVA, Adriana. A difusão do pensamento de Edgar Morin na Pesquisa em Educação Ambiental no Brasil: http://www.humanas.ufpr.br/site/evento/SociologiaPolitica/GTs-ONLINE/GT6\%20 online/EixoVI/florestan-fernandes-RenataOliveiraSantos.pdf 
Os desafios da educação ambiental são múltiplos e partem de um problema ainda não resolvido desde seu surgimento, decorrente de sua natureza interdisciplinar:a dificuldadede sistematiza-lo, ante a ausência de um referencial teórico, que tem sido, cada vez mais, evidenciado com o advento das novas tecnologias da informação e comunicação.

Os pesquisadores das ciências educacionais destacam a necessidade de se construir um método de educação ambiental adaptado as realidades regionais, as diferentes faixas etárias e as realidades sociais dos alunos; capaz de construir novos hábitos e atitudes em prol do meio ambiente. 0 estágio atual brasileiro da educação ambiental também está centrado neste esforço.

Ainda assim, observa-se que as ações em educação ambiental são desarticuladas, e não tem sido capazes de desencadear uma nova visão de mundo. Aos docentes cabe o desafio de se capacitarem para educar ambientalmente nesta nova realidade e nova forma de relações sociais, pois é essencial que o docente seja um usuário experimentado do meio ambiente digital, para ser capaz de promover a formação de atitudes ecológicas e cidadãs de seus alunos, capazes de identificar e compreender os problemas ambientais (USUEDA e outros).

\section{EDUCAÇÃO AMBIENTAL NO MEIO AMBIENTE DIGITAL}

Chega-se ao ponto de encontro da educação ambiental com o direito digital, partindo do diálogo já apresentado do direito para a construção da disciplina da educação para o meio ambiente no Brasil e no mundo, até chegar à compreensão do meio ambiente digital como um espaço de efetivação dos direitos fundamentais ao meio ambiente e à educação.

O objetivo da educação ambiental é promover a construção de valores, conhecimentos, habilidades, atitudes e competências para a defesa e proteção do meio ambiente. 0 do direito digital é organizar "parâmetros jurídicos específicos destinados a tute- 
lar o conteúdo da comunicação social" (FIORILLO, 2015). Uma dasinterfaces do direito ambiental e o direito eletrônico, está no uso das novas tecnologias da informação, como meio para a promoção da educação ambiental, com o objetivo de se alcançar o direito de todos a um meio ambiente ecologicamente equilibrado.

Analisar-se-a o meio ambiente digital como um espaço propício para a concretização do desenvolvimento sustentável, até se alcançar a sobreposição dos temas e compreende-lo a partir da efetivação do direito à educação ambiental no meio ambiente digital.

\subsection{MEIO AMBIENTE DIGITAL COMO ESPAÇO DE EFETIVAÇÃO DO DIREITO À EDUCAÇÃO}

Não são poucos os estudos que refletiram sobre a incidência das novas tecnologias na educação. Estudiosos das mais diversas áreas do conhecimento debruçaram-se sobre o tema numa tentativa de sistematiza-lo, ainda que ao fim se busque mais do que isso, encontrar um referencial teórico para o tema, como já abordado.

Um dos mais detalhados estudos de USEDA e outros, compilou em 2015 as experiências docentes de educação no espaço digital, para apresentar o "estado da arte" das estratégias, atitudes e comunicações até então adotadas pelos docentes no meio ambiente digital.Os estudiosos perceberam que atualmente para se promover a edução formal é necessário (a) empenho dos docentes para conhecer e utilizar as tecnologias da informação e comunicação, especialmente visto como um elemento transversal na gestão do conhecimento; (b) a compreensão da nova relação que se estabelece entre docentes e estudantes; e, (c) compreensão do conhecimento como reconhecimento dos indivíduos, das realidades e da sociedade.

A capacitação daqueles que irão manusear as novas tecnologias é essencial para se estabelecer a comunicação entre a comunidade acadêmica ou agente que irá propor atividades de 
educação ambiental. Este esforço está marcado pelo evidente descompasso entre os jovens e os professores mais tradicionais e resistentes à introdução de práticas pedagógicas no meio ambiente digital.

Para além da educação formal, observa-se que a internet é uma dessas ferramentas das ditas novas tecnologias capaz de "transformar consciências", por meio de múltiplas possibilidades de expressão, sendo um espaço de manifestação multicultural (FIORILLO, 2015, p.129).

As novas gerações estão integralmente integradas com a mundo digital, fazendo uso dele para sua comunicação diária. Na educação formal, nem todos os educadores tem acesso em sala de aula e no ambiente acadêmico como ferramenta de trabalho, mas como equipamento pessoal para comunicação interpessoal, estima-se que $80 \%$ dos domicílios no Brasil façam uso da internet através de telefones celulares (IBGE, 2014), e 76,6\% através de computadores.

A incidência da internet marca a história recente do desenvolvimento da educação, especialmente a ambiental, destacando o papel da rede na criação de uma nova cultura, com a aplicação tecnológica reforçando a ideia de comunidade mundial e de globalização, que marca as questões ambientais. Internet como recurso especialmente útil para a educação ambiental na medida em que pode servir para a construção de uma consciência planetária sobre os problemas ambientais e sobre a necessidade de se adotar soluções transnacionais.

As novas formas de comunicação propiciadas a partir desta nova conformação da sociedade impactou as relações sociais, e a educação precisa acompanhar este movimento. Patrícia Peck (PINHEIRO, 2016) destaca o viés educativo do direito digital, a partir destas novas relações: "há uma faceta educacional muito forte no estudo do direito digital e em sua aplicação, inclusive em escolas, seja no ensino fundamental ou médio". 
Se a comunicação é um ato humano de reflexão, construção do conhecimento e pensamento, com as tecnologias do mundo globalizado, o ser humano encontrou outras formas de comunicação, difusão e construção do saber. E se informação é um processo de educação, o uso das Tecnologias da Informação e Comunicação TIC são mediadoras da construção e do acesso ao conhecimento.

0 meio ambiente digital surge como um novo espaço de relações sociais e de efetivação do direito fundamental ao meio ambiente ecologicamente equilibrado das presentes e futuras gerações, e o direito de todos à educação. 0 espaço digital é o "novo espaço de troca" 21 , de construção e de formação das relações sociais na sociedade da informação.

\subsection{EFETIVIDADE DO DIREITO À EDUCAÇÃO AMBIENTAL NO MEIO AMBIENTE DIGITAL}

Em 1997 uma equipe europeia, denominada de EuroSymbio$\mathrm{ses}^{22}$, publicou um informativo sobre a incidência da internet no desenvolvimento da educação ambiental, e destacou o papel da rede para a uma nova cultura mundial, globalizada. 0 advento das tecnologias da informação abriu o mundo acadêmico às massas, se não democratizando o conhecimento, ao menos o acesso as

21 "Questiona-se assim, a posição do meio ambiente cultural na tutela jurídica do fenômeno que no século XXI constitui a sociedade da informação. É conhecido que a evolução das tecnologias da informação propiciou mudanças reveladoras de novo processo civilizatório que, com o advento da internet, criou novo espaço de troca e de formação de relações sociais: o espaço digital. As redes virtuais são marcadas pelo caráter difuso e introduzem na sociedade uma temporalidade aberta, que entende o momento presente como conectado com o tempo das futuras gerações. Nesse sentido é que avaliamos a dimensão funcional da comunicação na contemporaneidade, demonstrando como os usos da internet apresentam um dos campos de investigação mais importantes do direito ambiental brasileiro na atualidade". FIORILLO, Princípios Constitucionais do Direito da Sociedade da Informação, p. 124.

22 O Projeto EuroSymbioses foi formado a partir da iniciativa de quarto organismos europeus: rede Idée e Associação Natureza e Lazer da Bélgica, Rede Escola e Natureza da França, Associação ASPEA de Portugal. Suas atividades foram realizadas no quaro do programa SÓCRATES da Comissão Européia. 
informações ambientais produzidas por estudiosos e docentes sobre uma nova forma e num novo espaço.

Todavia, ainda que as tecnologias da informação e comunicação permitam, de forma antes inimaginável, aproximarmos a experiência globalizada e o conhecimento, sem método e intencionalidadea rede não e capaz por si só de solucionar problemas ambientais e sociais contemporâneos.

O Prof. Fiorillo destaca na sua obra "Princípios Constitucionais do Direito da Sociedade da Informação" (2015), que há imensas desigualdades sociais no Brasil e no mundo, que impedem o desenvolvimento do uso dos meios informáticos. Desta forma, a escola da sociedade da informação não deve se limitar a ser uma mera transmissora de conhecimentos, deve, ademais, compensar as desigualdades, fomentar o espirito critico, a capacidade para processar e estruturar as informações, para melhorar os processos básico de desenvolvimento do ser humano como a comunicação, a criação e a capacidade de compreender os problemas ambientais e agir para evita-los ou soluciona-los.

No encontro da Política Nacional de Educação Ambiental - PNEA, estabelecida para atender a dois preceitos constitucionais - direito à educação e dever de proteção do meio ambiente, com o Marco Civil da Internet, depreende-se os elementos para demonstrar que o meio ambiente digital é um espaço adequado para efetivação deste direito e concretização deste dever.

A PNEA inscreve com um dos objetivos fundamentais da educação ambiental, o fomento e o fortalecimento de sua integração com a ciência e tecnologia (art. 5ํㅜ) ), devendo ser promovidas ações na educação em geral e na educação escolar "estudos, pesquisas e experimentações para a difusão de conhecimentos, tecnologias e informações sobre a questão ambiental" (art. 8ํㅜ). O Brasil ainda não desenvolveu uma plataforma na rede para atender a esta norma, conta apenas com páginas governamen- 
tais dedicadas a compilar os documentos oficiais sobre o tema e históricos da educação ambiental.

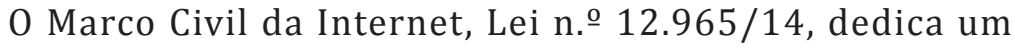
capítulo às diretrizes para a atuação do Poder Público no desenvolvimento da internet no país. No tocante à educação no meio ambiente digital retoma normas já inscritas em outras legislações infraconstitucionais, a exemplo da PNEA. Porém, nosso país enfrenta amplas dificuldades relacionadas ao direito social de educação, longe de lhe alcançar universalidade, ainda tem que se adaptar às novas tecnologias, que depende de capacitação e ferramentas adequadas. Portanto, ainda que pareça repetitivo trazer aqui novamente a necessidade de inclusão da educação no meio ambiente digital, reforça-se a necessidade de orientação dos usuários da rede, "como ferramenta para o exercício da cidadania, a promoção da cultura e o desenvolvimento tecnológico" (art. 26).

Os estudos europeus da década de 90 eram otimistas ao apresentar a internet como um recurso essencialmente útil para a educação ambiental, na medida em que pode dar alcance planetário à conscientização mundial da questão ambiental e seus problemas. 0 que tem se observado é que o processo de globalização não é uniforme, nem geograficamente, nem nos campos de aplicação. Se amplamente desenvolvido para o mercado financeiro e de capitais, no âmbito da educação não há este alcance. No Brasil estas diferenças são ainda mais acentuadas, "as imensas desigualdades sociais impedem o desenvolvimento homogêneo do uso dos meio informáticos" (FIORILLO, 2015, p.131).

Mas a atual ausência de homogeneidade no alcance e na construção do conhecimento em rede não lhe tira sua função social de exercício da cidadania, através da informação e, consequentemente, da construção do conhecimento para o pleno exercício de seu direito constitucional à educação.

0 direito à educação enquanto direito fundamental de segunda geração de prestação social do Estado, na sistematização 
feita por SARLET (2009), na atual sociedade da informação impulsiona o ambiente acadêmico a encontrar novos meios para sua efetividade. Ao lhe dar efetividade, o meio ambiente digital, no cumprimento de sua função social, e alcançar a educação ambiental, torna-se um espaço adequado para conscientização pública para a proteção do meio ambiente.

\section{CONSIDERAÇÕES FINAIS}

0 presente trabalho almejou traçar um paralelo entre os estudos de direito ambiental sobre educação ambiental e o direito digital, e encontrar seu ponto de convergência. As conclusões aqui apresentadas não pretendem esgotar o tema, e sim propor reflexões para aprimorar e aprofundar um marco teórico da educação ambiental, especialmente, a partir das novas tecnologias da informação e comunicação, como espaço para efetivação do direito à educação.

De forma sistematizada, conclui-se que:

- A educação ambientaltem papel estratégico no processo educacional e de proteção ambiental, propiciando a formação de valores e atitudes associadas a sustentabilidade ambiental e equidade social;

- As tecnologias da informação e do conhecimento tornaram-se mediadoras da construção e acesso ao conhecimento pertinente, equitativo e de qualidade na sociedade da informação;

- O uso das novas tecnologiasé necessário nas escolas, como reflexo da nova sociedade, como estratégia atrativa de comunicação capaz de construir uma nova visão de mundo globalizado;

- Ao docente cumpre problematizar o saber ambiental no suporte digital, colocando o aluno como interlocutor e criador do conhecimento para a construção de atitudes 
ecológicas, como um espaço de manifestação do pensamento, criação, expressão e informação;

- É urgente a integração das novas tecnologias da informação e comunicação nos ambientes escolares, sob pena de se perder o contato com as novas gerações;

- Há necessidade de se desenvolver uma metodologia para a educação ambiental no meio ambiente digital, e atender as bases propostas no Programa Nacional de Educação Ambiental, e de alterar a cultura escolar autoritária, para uma cultura participativa, tão trabalha na atual fase dos estudos de educação;

- Diante dos problemas ambientais que são mundiais e transfronteiriços, o meio ambiente digital, diante do seu alcance, é ferramenta adequada capaz de promover transformação mundial para uma sociedade sustentável;

- Por fim, o direito à educação, enquanto direito fundamental, encontra espaço de efetivação no meio ambiente digital, na sua função social, ao alcançar à todos o acesso às informações ambientais, à educação ambiental, como exercício do direito/dever a proteção ambiental.

\section{REFERÊNCIAS}

BICALHO, Lucinéia; OLIVEIRA, Marlene.Aspectos conceituais da multidisciplinaridade e da interdisciplinaridade e a pesquisa em ciência da informação. Revista Eletrônica de Biblioteconomia e Ciência da Informação, v. 16, n. 32, p. 1-26, 2011

CARTEA, Pablo A. M. La investigatióneneducacion ambiental y lasnuevas tecnologias de lainformación y lacomunicación. Revista Eletrônica Teoria de laEducacuón, 2009.

DUARTE, Clarice. A educação como um direito fundamental de natureza social. Revista de Educação Social, Campinas, vol. 28, n. 100, p. 691-713.

FIORILlo, Celso Antonio Pacheco. O Marco Civil da Internet e o Meio Ambiente Digital na Sociedade da Informação: comentários à Lei $n$. 12.965/2014. São Paulo: Saraiva, 2015. 
. Princípios Constitucionais do Direito da Sociedade da Informação: a tutela jurídica do meio ambiente digital. São Paulo: Saraiva, 2015.

GODOY, Larissa R. C. 0 modelo de gestão e o financiamento de áreas protegidas nos Estados Unidos da América, Revista de Direito Ambiental, RT, jan-mar2015, vol. 77, p. 361/414.

SARLET, Ingo Wolfgang. A Eficácia dos Direitos Fundamentais: uma teoria dos direitos fundamentais na perspectiva constitucional. 10. ed. rev. e amp. Porto Alegre: Livraria do Advogado, 2009.

LEFF, Enrique. Ecologia, capital e cultura: a territorialização da racionalidade ambiental. Petrópolis: Vozes, 2009.

MACHADO, Paulo Affonso L. Direito Ambiental Brasileiro. São Paulo: Malheiros, 22aㅡ. ed., 2014.

MOREIRA, Antônio Flávio. Políticas e Práticas. Campinas: Papirus, 1999.

PEDRINI, Alexandre. Educação Ambiental. Rio de Janeiro: Vozes, 1997.

PINHEIRO, Patrícia Peck. O Direito Digital como Paradigma de uma Nova Era. Os "novos" direitos no Brasil. WOLKMER, A. LEITE, J.R.M. (org). Saraiva: São Paulo, 3oed., 2010.

RODRIGUES, Gelze; COLESANTI, Marlene. Educação Ambiental e as Novas Tecnologias da Informação e Comunicação. Revista Sociedade \& Natureza, Uberlândia, 20 (1): 51-66, jun. 2008.

SIQUEIRA JR., Paulo Hamilton. Direito Informacional: direito da sociedade da informação. Revista dos Tribunais, vol. 859, p. 743-759. 